\title{
Shaping Morphogen Gradients by Proteoglycans
}

\author{
Dong Yan $^{1}$ and Xinhua Lin ${ }^{1,2}$ \\ ${ }^{1}$ Division of Developmental Biology, Cincinnati Children's Hospital Medical Center, Cincinnati, Ohio 45229 \\ ${ }^{2}$ State key Laboratory of Biomembrane and Membrane Biotechnology, Institute of Zoology, Chinese Academy \\ of Sciences, Beijing 100101, China \\ Correspondence: xinhua.lin@cchmc.org
}

During development, secreted morphogens such as Wnt, Hedgehog $(\mathrm{Hh})$, and BMP emit from their producing cells in a morphogenetic field, and specify different cell fates in a direct concentration-dependent manner. Understanding how morphogens form their concentration gradients to pattern tissues has been a central issue in developmental biology. Various experimental studies from Drosophila have led to several models to explain the formation of morphogen gradients. Over the past decade, one of the main findings in this field is the characterization of heparan sulfate proteoglycan (HSPG) as an essential regulator for morphogen gradient formation. Genetic and cell biological studies have showed that HSPGs can regulate morphogen activities at various step including control of morphogen movement, signaling, and intracellular trafficking. Here, we review these data, highlighting recent findings that reveal mechanistic roles of HSPGs in controlling morphogen gradient formation.

$\mathrm{E}_{\mathrm{sp}}^{\mathrm{m}}$

mbryonic development involves many atial and temporal patterns of cell and tissue organization. These patterning processes are controlled by gradients of morphogens, the "form-generating substances" (Tabata and Takei 2004; Lander 2007). Secreted morphogen molecules, including members of Wnt, Hedgehog (Hh), and transforming growth factor- $\beta$ (TGF- $\beta$ ) families, are generated from organizing centers and form concentration gradients to specify distinct cell fates in a concentration-dependent manner. Understanding how morphogen gradients are established during development has been a central question in developmental biology. Over the past decade, studies in both Drosophila and vertebrates have yielded important insights in this field. One of the important findings is the characterization of heparan sulfate proteoglycan (HSPG) as an essential regulator for morphogen gradient formation. In this review, we first discuss various models for morphogen movement. Then, we focus on the functions of HSPGs in morphogen movement, signaling, and trafficking.

\section{MODELS OF MORPHOGEN GRADIENT FORMATION}

\section{Restricted Diffusion}

The simplest mechanism for morphogen gradient formation is passive diffusion. Studies of how inert molecules spread in early Drosophila

Editors: James Briscoe, Peter Lawrence, and Jean-Paul Vincent

Additional Perspectives on Generation and Interpretation of Morphogen Gradients available at www.cshperspectives.org

Copyright (C) 2009 Cold Spring Harbor Laboratory Press; all rights reserved; doi: 10.1101/cshperspect.a002493

Cite this article as Cold Spring Harb Perspect Biol 2009;1:a002493 


\section{Yan and X. Lin}

syncytium embryos suggested that intracellular morphogens, such as Bicoid and Nanos, may form gradients by free diffusion (Gregor et al. 2005). However, simple diffusion alone cannot explain the graded distribution of secreted morphogens such as Wg, Hh, and Decapentaplegic (Dpp). It was shown that in wing discs, a secreted form of green fluorescent protein (GFP) fails to form a concentration gradient (Entchev et al. 2000). Furthermore, the restraint of morphogen spreading along the epithelial cell surface seems to be important as the folding of developing tissues, such as Drosophila leg disc, poses a problem if morphogen spreading were to occur out of the plane of
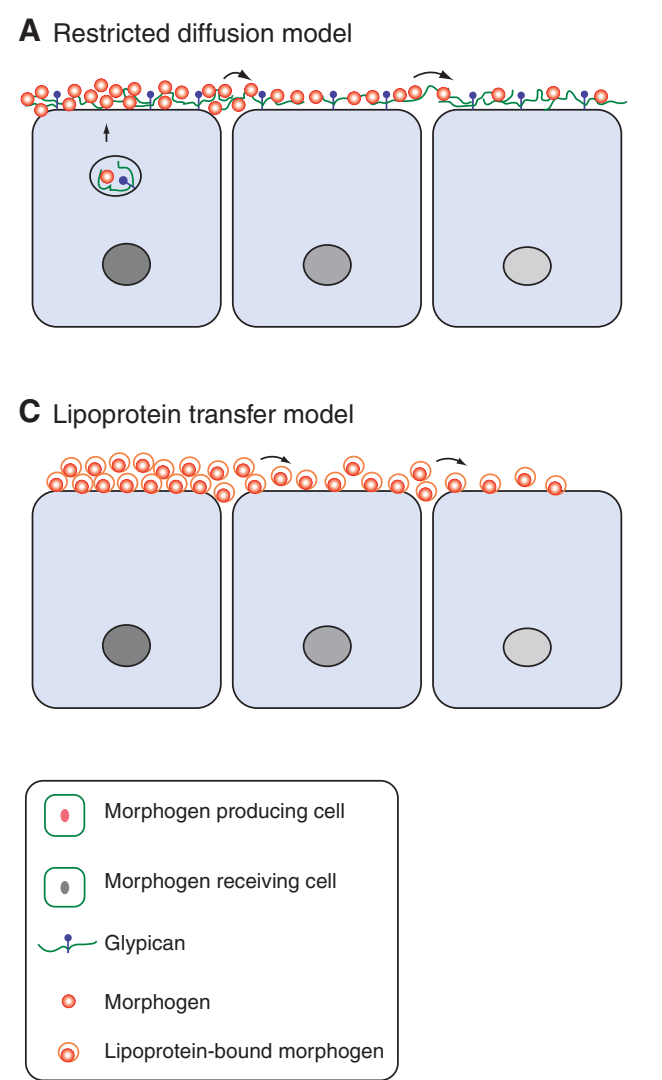

the epithelial cell layer through free diffusion. Recent experimental and theoretical studies favor a restricted diffusion model in which secreted morphogen molecules interact with their receptors and extracellular matrix (ECM) proteins, especially HSPGs (Lander et al. 2002; Lin 2004; Tabata and Takei 2004; Zhu and Scott 2004) (Fig. 1A). The restricted diffusion model fits well for the movement of $\mathrm{Wg}, \mathrm{Hh}$, and Dpp molecules in the wing disc (Bellaiche et al. 1998a; Strigini and Cohen 2000; Teleman and Cohen 2000; Baeg et al. 2004; Belenkaya et al. 2004; Han et al. 2004b; Han et al. 2005; Callejo et al. 2006; Hufnagel et al. 2006). Interaction of morphogens with their cell
B Planar transcytosis model

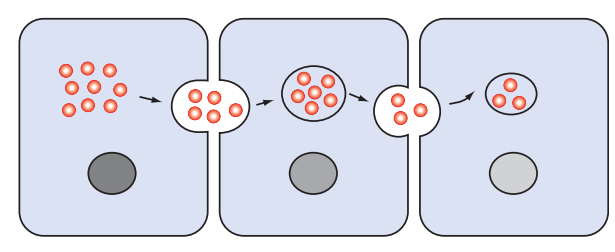

D Cytoneme model

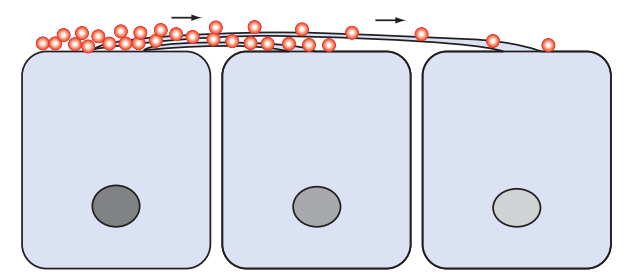

Figure 1. Four models of morphogen gradient formation. (A) A model for restricted diffusion. Morphogens diffuse extracellularly by interaction with extracellular matrix proteins such as HSPGs, as well as other cell surface receptors and coreceptors. (B) A model for planar transcytosis. Morphogens are actively transported through repeated rounds of endocytosis and resecretion in receiving cells. $(C)$ A model for lipoprotein transfer. Lipid-modified morphogens are packed into lipoprotein particles and transported in these vesicles. (D) A model for cytonemes. Morphogen receiving cells extend long, actin-based filopodia from the apical surface, called cytonemes, toward the morphogen source. 
surface receptors can further shape morphogen gradients. For example, Hh receptor Patched (Ptc) limits the $\mathrm{Hh}$ gradient range by internalizing $\mathrm{Hh}$ through endocytosis and targeting it to lysosomal degradation (Chen and Struhl 1996; Torroja et al. 2004). On the other hand, Wg receptor dFrizzled2 (dFz2), binds and stabilizes extracellular Wg (Cadigan et al. 1998; Lecourtois et al. 2001; Baeg et al. 2004). A numerical analysis has suggested that such regulation by morphogen receptors will lead to enhanced degradation of morphogens close to the source and generate a robust gradient (Eldar et al. 2003). Binding of morphogen molecules to HSPGs restricts their diffusion along the surface of receiving cells, preventing them from loss to the extracellular space or aberrant signaling to other layers of cells such as peripodial cells (Callejo et al. 2006; Gallet et al. 2006). Moreover, HSPGs can provide a signaling platform for morphogens to interact with other important components, because HSPGs are able to bind to many cell surface co-receptors and secreted proteins such as Ihog (interference hedgehog; a co-receptor for Hh) (McLellan et al. 2006; Yao et al. 2006), Lipoprotein (binds to $\mathrm{Hh} / \mathrm{Wg}$ ) (Eugster et al. 2007), Shifted (binds to Hh) (Glise et al. 2005; Gorfinkiel et al. 2005), and Crossveinless2 (binds to Dpp) (Serpe et al. 2008). We discuss in detail the roles of HSPGs in morphogen gradient formation in the next section.

\section{Planar Transcytosis}

The planar transcytosis model explains that morphogens move from the source by active transport through repeated endocytosis and resecretion (Fig. 1B). Early studies using a temperature-sensitive mutation of shibire (Drosophila Dynamin, a GTPase required for clathrin-dependent endocytosis) suggest that endocytosis might play a role in $\mathrm{Wg}$ movement in Drosophila embryonic epidermis (Bejsovec and Wieschaus 1995; Moline et al. 1999). Another piece of evidence supporting the planar transcytosis model comes from analyses of movement of a biologically active Dpp-GFP
Shaping Morphogen Gradients by Proteoglycans

fusion protein in wing discs (Entchev et al. 2000). When a shibre mutant clone is generated after a pulse induction of Dpp-GFP expression, Dpp-GFP is unable to transport to the cells behind the clone (Entchev et al. 2000), arguing that Dpp movement is controlled by planar transcytosis. However, several subsequent studies suggest that planar transcytosis is not a major mechanism for morphogen movement. Strigini and Cohen showed that Dynamin-mediated endocytosis is not required for Wg movement in wing discs (Strigini and Cohen 2000). Moreover, a role of planar transcytosis in Dpp movement was also challenged by both mathematical and experimental studies (Lander et al. 2002; Belenkaya et al. 2004). A mathematical study argues that the observed defects on Dpp-GFP movement after the shibre clones actually also fits the restricted diffusion model if receptor-mediated internalization is taken into consideration (Lander et al. 2002). In addition, experimental data from our lab favor Dpp-GFP movement by restricted diffusion because it was found that Dpp-GFP movement was not blocked by shibre clones, but rather by HSPG mutated clones (Belenkaya et al. 2004). However, a recent kinetic study using fluorescence recovery after photobleaching (FRAP) showed that Dpp-GFP requires Dynamin function to spread into the photobleached region (Kicheva et al. 2007). Further analysis is required to determine the exact contribution of planar transcytosis and restricted diffusion in Dpp gradient formation.

\section{Other Models}

Two other models are also proposed to explain morphogen movement. Eaton and her colleagues suggested that movement of morphogens such as $\mathrm{Wg}$ is mediated by membrane vesicles called argosomes (Greco et al. 2001). Recently, they revised this model and proposed that lipid-linked morphogens, such as Hh and $\mathrm{Wg}$, are carried and transported by lipoprotein particles in Drosophila wing discs (Panakova et al. 2005) (Fig. 1C). Lipoproteins are composed of a central core of neutral lipids and an 
outer layer of polar phospholipids, cholesterol, and very large embedded proteins called apolipoproteins. Lipoproteins are well-known to transport cholesterol and triacylglycerols in body fluids; therefore, it is intriguing that they might have a novel function in transporting morphogens as well. It was shown that lipophorin, the Drosophila apolipoprotein, cofractionates with $\mathrm{Hh}$ and $\mathrm{Wg}$ in biochemical experiments (Panakova et al. 2005). Lipophorin colocalizes with $\mathrm{Hh}$ and $\mathrm{Wg}$ in wing disc, whereas knockdown of lipophorin by RNAi reduces long-range, but not short-range, signaling activity of $\mathrm{Hh}$ and $\mathrm{Wg}$. A recent study showed that a package of $\mathrm{Hh}$ in lipoprotein particles is essential for Hh stability and proper spreading (Callejo et al. 2008). Furthermore, lipoprotein is likely to mediate morphogen movement in Drosophila and vertebrate embryos, as Drosophila egg yolk contains plentiful lipophorin (Kutty et al. 1996), and lipoprotein is highly expressed and important in the yolk sac of early mouse embryos (Farese et al. 1996; Willnow et al. 2007). It is important to note that lipoprotein can interact with cell surface HSPGs (Eugster et al. 2007). Therefore, lipoprotein may work together with HSPGs to contribute to morphogen movement by a restricted diffusion mechanism.

Kornberg and colleagues proposed that direct cell contact through cytonemes may control morphogen movement (RamirezWeber and Kornberg 1999; Hsiung et al. 2005). Cytonemes are apical actin-based filopodia extending from Drosophila wing disc pouch (Ramirez-Weber and Kornberg 1999; Hsiung et al. 2005). Through cytonemes, all cells, regardless of their positions in the wing pouch, can directly contact with the morphogen producing cells (Fig. 1D). They showed that the Dpp receptor Thickveins forms mobile punctae moving along cytonemes (Hsiung et al. 2005), arguing that Dpp and its receptor complex might travel along the cytoneme surface in the signal receiving cells. It remains to be determined whether morphogen ligands are associated with cytonemes and how a morphogen gradient is formed in these structures.
The above models are not mutually exclusive. They may work hand in hand to fine tune the amplitude and range of morphogen gradients. One challenge in the field is that although we can visualize the morphogen gradient by antibody staining or GFP fusion protein, we do not know the pool of morphogen molecules that is responsible for signaling activity. For example, it is unclear whether apical or basallateral portions of $\mathrm{Wg}, \mathrm{Hh}$, and Dpp are directly involved in signaling (Callejo et al. 2006; Gallet et al. 2006; Marois et al. 2006; Kicheva et al. 2007; Gallet et al. 2008). Further studies with advanced techniques such as fluorescence resonance energy transfer (FRET) to measure ligand-receptor interaction may help understand these important questions. Moreover, data on morphogen regulation in vertebrates are very limited. Current studies in vertebrates suggest that morphogen movement is controlled by a diffusion mechanism, possibly through interaction with their receptors and ECM. Examples include Xenopus activin (McDowell et al. 2001), nodal-related 2 (Williams et al. 2004), sonic hedgehog (Saha and Schaffer 2006), and retinoic acid (White et al. 2007).

\section{ROLES OF HSPGS IN MORPHOGEN GRADIENT FORMATION}

In this section, we focus on the roles of HSPGs in morphogen gradient formation. We discuss findings derived from Drosophila as well as vertebrates.

\section{HSPG Biochemistry}

HSPGs are cell-surface and ECM macromolecules that comprise a protein core to which heparan sulfate (HS) glycosaminoglycan (GAG) chains are attached (Bernfield et al. 1999; Esko and Selleck 2002). HSPGs can be classified into several families based on their core protein structure (Fig. 2). Glypicans and syndecans are cell surface HSPGs and are linked to the plasma membrane by a glycosylphosphatidyl inositol (GPI) anchor or a transmembrane domain, respectively. Perlecans are 

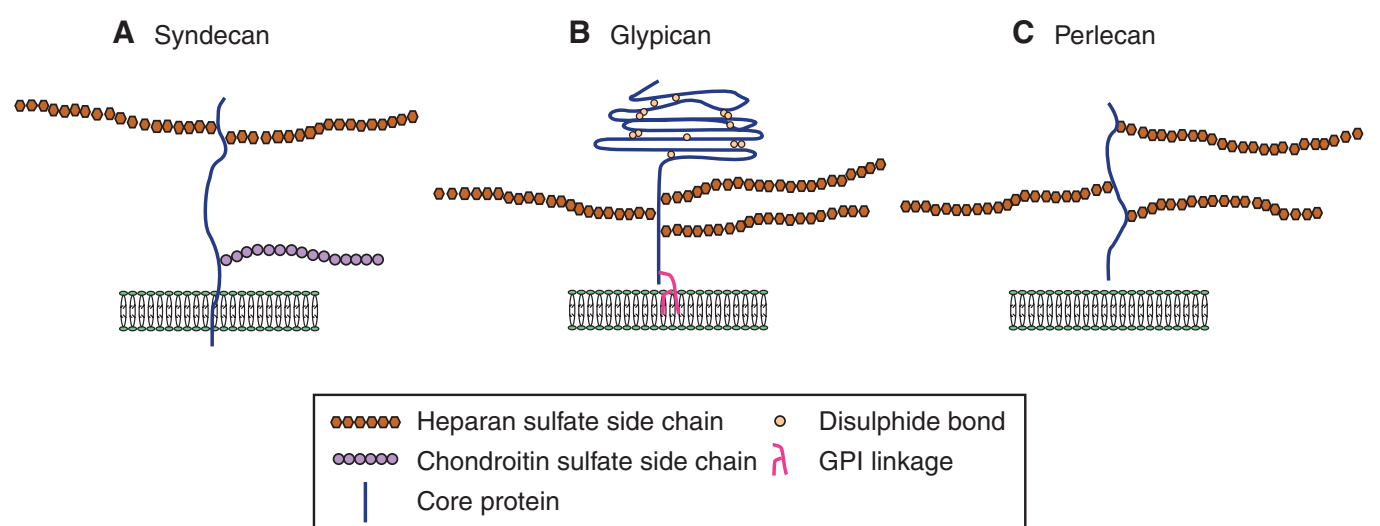

Figure 2. The three main classes of cell-surface heparan sulfate proteoglycans. (A) Syndecan core proteins are transmembrane proteins that contain a highly conserved carboxy-terminal cytoplasmic domain. Heparan sulfate (HS) chains attach to serine residues distal from the plasma membrane. Some syndecans also contain chondroitin sulfate (CS) chain(s) that attaches to serine residue(s) near the membrane. $(B)$ The glypican core proteins are disulphide-stabilized globular core proteins that are linked to the plasma membrane by a glycosylphosphatidylinositol (GPI) anchor. HS chains link to serine residues adjacent to the plasma membrane. $(C)$ Perlecans are secreted HSPGs that carry HS chains.

secreted HSPGs that are mainly distributed in the ECM. Although glypicans and perlecans exclusively bear HS GAG chains, syndecans are decorated with both HS and chondroitin sulfate (CS). All three families of HSPGs are evolutionarily conserved from vertebrates to Drosophila and Caenorhabditis elegans. The Drosophila genome encodes two glypicans (division abnormally delayed [Dally] and Dally-like [dlp]) (Nakato et al. 1995; Khare and Baumgartner 2000; Baeg et al. 2001), a single syndecan (sdc) (Spring et al. 1994; Johnson et al. 2004; Steigemann et al. 2004), and a single perlecan (terribly reduced optic lobes [trol]) (Datta 1995; Voigt et al. 2002). Recently, accumulated evidence suggests that glypicans Dally and Dlp play major roles in regulating gradient formation of morphogens, including Wg, Hh, and Dpp (Lin 2004).

To date, most of the HSPG studies have shown the importance of their HS chains. HS chains are long unbranched polysaccharides synthesized in the Golgi apparatus and contain repeating disaccharide units of glucosamine and uronic acid (Esko and Selleck 2002). HS chain biosynthesis is initiated at the GAG attachment sites of the core protein, which contains 2-4 Ser-Gly sequences. As shown in Figure 3, various glycosyltransferases and modification enzymes are involved in the polymerization and modification processes of HSPG biosynthesis. These enzymes are conserved in Drosophila and vertebrates (Esko and Selleck 2002; Nybakken and Perrimon 2002; Lin and Perrimon 2003), and mutations of these enzymes have been shown to cause defects in morphogen signaling and its gradient formation (Lin 2004).

\section{Roles of HSPGs in Wg Signaling and Distribution}

In the wing disc, $\mathrm{Wg}$ is secreted from the dorsal/ ventral $(D / V)$ border and acts as a long-range morphogen by inducing the expression of $\mathrm{Wg}$ target genes, including senseless (sen), distalless $(\mathrm{dll})$, and vestigial $(\mathrm{vg})$ (Zecca et al. 1996; Neumann and Cohen 1997) (Fig. 4). The involvement of HSPGs in Wg signaling was first revealed by the isolation and analysis of sugarless $(\mathrm{sgl})$ and sulfateless ( $\mathrm{sfl}$ ) mutants in Drosophila (Binari et al. 1997; Hacker et al. 1997; Haerry et al. 1997; Lin and Perrimon 1999) (Fig. 3). Wg signaling is defective in $s g l$ and $s f l$ mutant embryos. In addition, Wg targetgene expression and extracellular $\mathrm{Wg}$ protein 
D. Yan and X. Lin

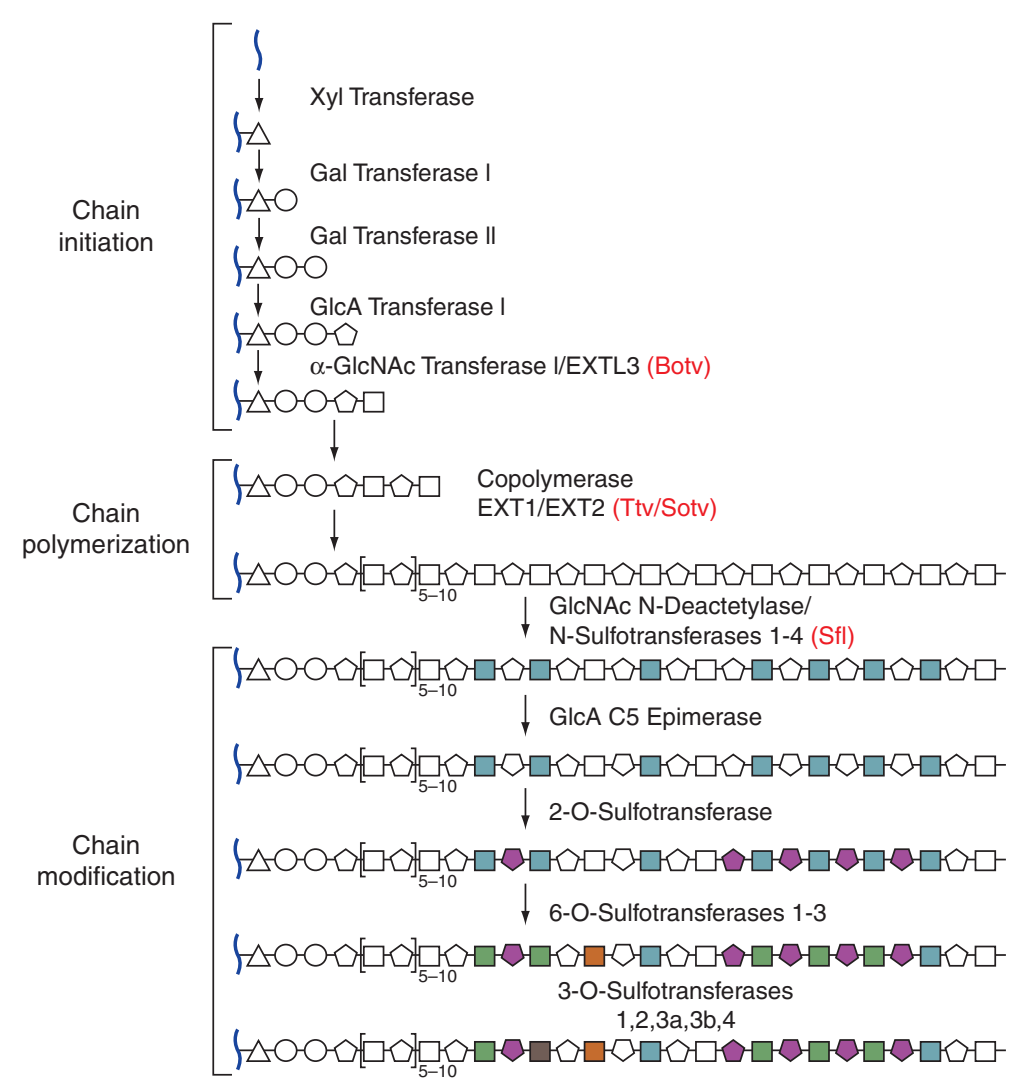

\begin{tabular}{|l}
$\int$ Core Protein $\triangle$ Xyl $\bigcirc$ Gal $\square$ GlcA $\square$ IdoA $\square$ GlcNAc \\
$\square$ N-Sulfo Glc $\square$ 2-O-Sulfo GlcA $\square$ 2-O-Sulfo IdoA $\square$ 2-O,N-Sulfo Glc \\
$\square$ 6-O-Sulfo Glc $\square$ 2-O,6-O,N-Sulfo Glc
\end{tabular}

Figure 3. Heparan sulfate chain biosynthesis. Heparan sulfate (HS) glycosaminoglycan (GAG) chains are synthesized on a core protein by the sequential action of individual glycosyltransferases and modification enzymes, in a three-step process involving chain initiation, polymerization, and modification. HS chain synthesis begins with the assembly of a linkage tetrasaccharide on serine residues in the core protein. This process is catalyzed by four enzymes (Gal transferase I-III and $\alpha$-GlcNAc transferase I), which add individual sugar residues sequentially to the nonreducing end of the growing chain. After the assembly of the linkage region, one or more $\alpha$-GlcNAc transferases add a single $\alpha 1,4$-linked GlcNAc unit to the chain, which initiates the HS polymerization process. HS chain polymerization then takes place by the addition of alternating GlcA and GlcNAc residues, which is catalyzed by the EXT family proteins. As the chain polymerizes, it undergoes a series of modifications that include GlcNAc $N$-deacetylation and $N$-sulfation, C5 epimerization of GlcA to IdoA, and variable $O$-sulfation at C2 of IdoA and GlcA, at C6 of GlcNAc and GlcNS units, and, occasionally, at C3 of GlcN residues. The HS GAG chains are $\sim 100$ or more sugar units long and have numerous structural heterogeneities. Four Drosophila enzymes, including Botv, Ttv, Sotv, and Sfl, which are homologs of vertebrate EXTL3, EXT1, EXT2, and $N$-deacetylase/ $N$-sulfotransferase, respectively, are highlighted in red. (Gal) galactose, (GlcNAc) $N$-acetylglucosamine, (GlcA) glucuronic acid, (GlcNS) N-sulfoglucosamine, (IdoA) iduronic acid. 

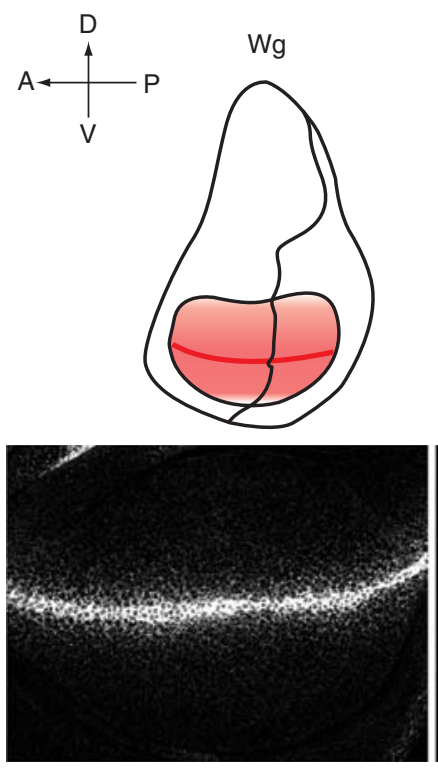
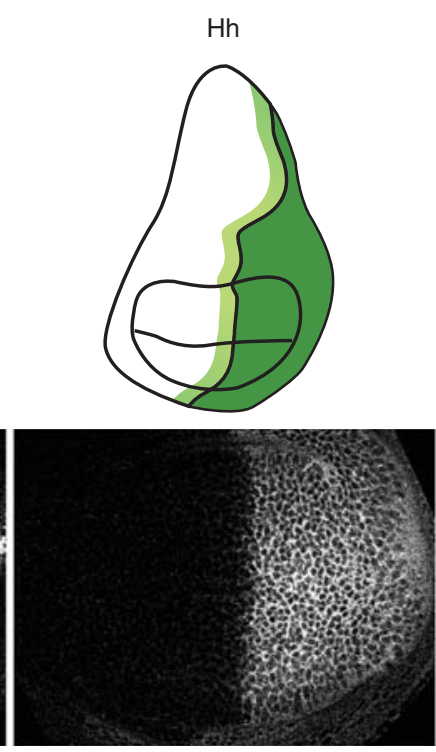
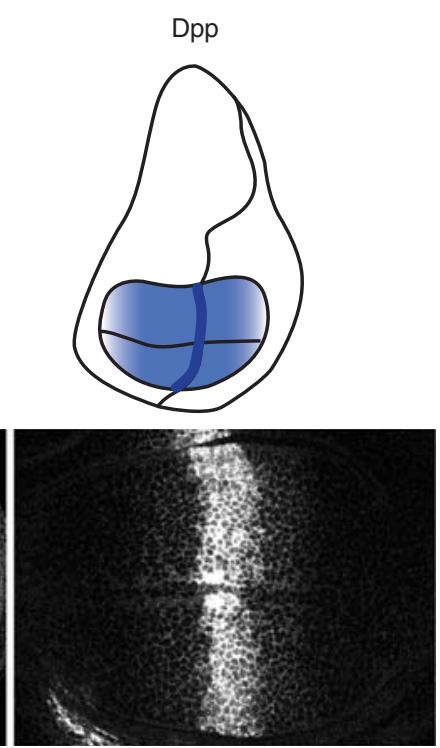

Figure 4. Distribution of Wg, Hh, and Dpp morphogens in the Drosophila wing imaginal disc. Drosophila wing imaginal discs are subdivided into anterior $(\mathrm{A})$ /posterior $(\mathrm{P})$ and dorsal $(\mathrm{D})$ /ventral $(\mathrm{V})$ compartments. In a third instar larvae wing disc, $\mathrm{Wg}$ is expressed at the $\mathrm{D} / \mathrm{V}$ border and acts as a long-range morphogen to organize $\mathrm{D} / \mathrm{V}$ patterning. Hh is expressed in the $\mathrm{P}$ compartment and moves in the A compartment to activate gene expression in a stripe of cells adjacent to the $\mathrm{A} / \mathrm{P}$ compartment boundary. Dpp acts as a long-range morphogen that controls the growth and patterning of wing cells along the $\mathrm{A} / \mathrm{P}$ axis beyond the central domain.

levels are reduced in $s f l$ mutant clones in the wing disc. Similarly, Wg signaling and its extracellular levels are also reduced in cells defective for Drosophila EXT proteins, including Tout-velu (Ttv), Sister of ttv (Sotv), and Brother of ttv (Botv), which are enzymes required for HS GAG biosynthesis (Fig. 3). Altogether, these data argue that HS GAG chains are required for $\mathrm{Wg}$ signaling, possibly by maintaining the local concentration of Wg at the cell surface (Lin 2004).

How do HSPGs regulate Wg movement? Previous studies have shown that Wg morphogen movement is regulated by a diffusion mechanism in the wing disc (Strigini and Cohen 2000). Importantly, Wg fails to move across a strip of cells defective for the HS GAG synthesis (Han et al. 2005). This result suggests that Wg can not freely diffuse in the extracellular matrix. Instead, Wg morphogen moves through the restricted diffusion mechanism by attaching to the GAG chains of HSPGs at the cell surface (Han et al. 2005) (Fig. 1A). Which HSPG core proteins are involved? It turns out that two glypicans, Dally and Dlp, play cooperative and distinct roles in modulating $\mathrm{Wg}$ signaling and distribution. First, removal of both Dally and Dlp leads to strong reduction of extracellular Wg, suggesting that Dally and Dlp are the major core proteins providing effective GAG chains (Han et al. 2005). Second, dally mutants show wing margin defects and show genetic interactions with Wg signaling components, arguing that Dally plays a positive role in $\mathrm{Wg}$ signaling in the wing disc (Lin and Perrimon 1999). Both Dally and Dlp bind Wg in cell culture. However, only Dlp overexpression causes Wg accumulation in imaginal discs (Baeg et al. 2001; Franch-Marro et al. 2005). These observations are consistent with a classical coreceptor role for Dally in Wg signaling. Dally could present Wg to dFz2 signaling receptor and this will lead to activation of signaling and rapid degradation of the complex (Lin and Perrimon 1999; Franch-Marro et al. 2005). Third, Dlp has a more intriguing activity in regulating $\mathrm{Wg}$ signaling and gradient. Loss-of-function and gain-of-function studies 
show that Dlp acts as a positive regulator in the regions of the wing disc distant from the site of $\mathrm{Wg}$ production. However, Dlp also acts as a negative regulator near the site of $\mathrm{Wg}$ production (Baeg et al. 2004; Kirkpatrick et al. 2004; Kreuger et al. 2004; Franch-Marro et al. 2005).

How could we explain the biphasic activity of Dlp in Wg signaling? Two models have been proposed. The first model is related to notum (also known as wingful), which encodes a member of the $\alpha / \beta$-hydrolase superfamily (Gerlitz and Basler 2002; Giraldez et al. 2002). Notum acts as a Wg antagonist and is induced by high-level $\mathrm{Wg}$ signaling in the $\mathrm{D} / \mathrm{V}$ boundary. Biochemical experiments showed that Notum can induce cleavage of Dlp at the level of its GPI anchor, causing shedding of Dlp from the cell surface. Thus, Notum-mediated cleavage may convert Dlp from a membrane-tethered co-receptor to a secreted antagonist (Kreuger et al. 2004). The second model is based on mathematical modeling of morphogen diffusion in the presence of glypicans and receptors on the cell surface (Hufnagel et al. 2006). The results indicate that the observed biphasic activity of Dlp would follow if the primary role of Dlp is to retain $\mathrm{Wg}$ on the cell surface and binding of Wg to Dlp competes with Wg signaling receptors. Consistent with this model, another study suggests that Dlp captures Wg but instead of presenting it to signaling receptors expressed in the same cell, it passes $\mathrm{Wg}$ to neighboring cells (Franch-Marro et al. 2005). Thus, the mechanism underlying biphasic activity of Dlp in Wg signaling is still unclear.

\section{Roles of HSPGs in Hh Signaling and Distribution}

In the wing disc, $\mathrm{Hh}$ is expressed in the entire posterior compartment and moves into the anterior compartment to signal (Tabata and Kornberg 1994). Hh acts as a short range morphogen to induce expression of target genes, including engrailed, $p t c$, and $d p p$, and pattern the central domain of the wing (Basler and Struhl 1994; Strigini and Cohen 1997). The first evidence for activity of HSPGs in Hh distribution came from the genetic analysis of $t$ tv (Bellaiche et al. 1998b). Hh signaling is diminished and Hh protein cannot be detected in the wing disc ttv mutant clones (Bellaiche et al. 1998a). Similar defects in Hh distribution were also observed in wing clones mutant for sfl, sotv, and botv (Bornemann et al. 2004; Han et al. 2004a; Takei et al. 2004). Importantly, $\mathrm{Hh}$ protein accumulates in front of HSPGdefective cells, arguing that $\mathrm{Hh}$ fails to move into the HSPG mutant cells (Takei et al. 2004). HSPGs might also control the stability of $\mathrm{Hh}$, because $\mathrm{Hh}$ levels are reduced in Hh-producing cells mutant for sotv or ttv (Bornemann et al. 2004). Furthermore, a narrow strip of $s f l$ or ttv mutant cells is sufficient to completely block $\mathrm{Hh}$ signaling in wild-type cells behind the mutant cells, suggesting that $\mathrm{Hh}$ fails to move across these HSPG-deficient cells (Han et al. 2004b). Similar results are observed in clones mutant for both dally and dlp (Han et al. 2004b). These data argue that Hh movement is mediated by restricted diffusion involving Dally and Dlp (Han et al. 2004b) (Fig. 1A).

In addition to the role in Hh movement, Dlp, but not other HSPG core proteins, has an essential role in receiving $\mathrm{Hh}$ signaling. In cellbased assays, Dlp is essential for Hh signaling, whereas RNAi knockdown of dally, sdc, trol, as well as HSPG enzymes including $t t v$, sotv, and botv, fails to disrupt the cells' response to $\mathrm{Hh}$ (Lum et al. 2003). Consistent with those observations, ectopic expression of $\mathrm{Hh}$ can rescue cuticle defects associated with HS GAG mutants including $\mathrm{sgl}, \mathrm{sfl}$, frc, and slalom (Selva et al. 2001; Luders et al. 2003; Perrimon et al. 2004), but it fails to restore Hh signaling activity in $d l p$ RNAi embryos (Desbordes and Sanson 2003). These results suggest that the core protein of Dlp is critical for Hh signaling activity, and potentially acts as an essential co-receptor.

Both $\mathrm{Hh}$ and $\mathrm{Wg}$ are lipid modified, and are tightly associated with the cell surface (Eaton 2006). The lipid modification of $\mathrm{Hh}$ is required for its interaction with HSPGs (Bellaiche et al. 1998a; Callejo et al. 2006; Gallet et al. 2006). 


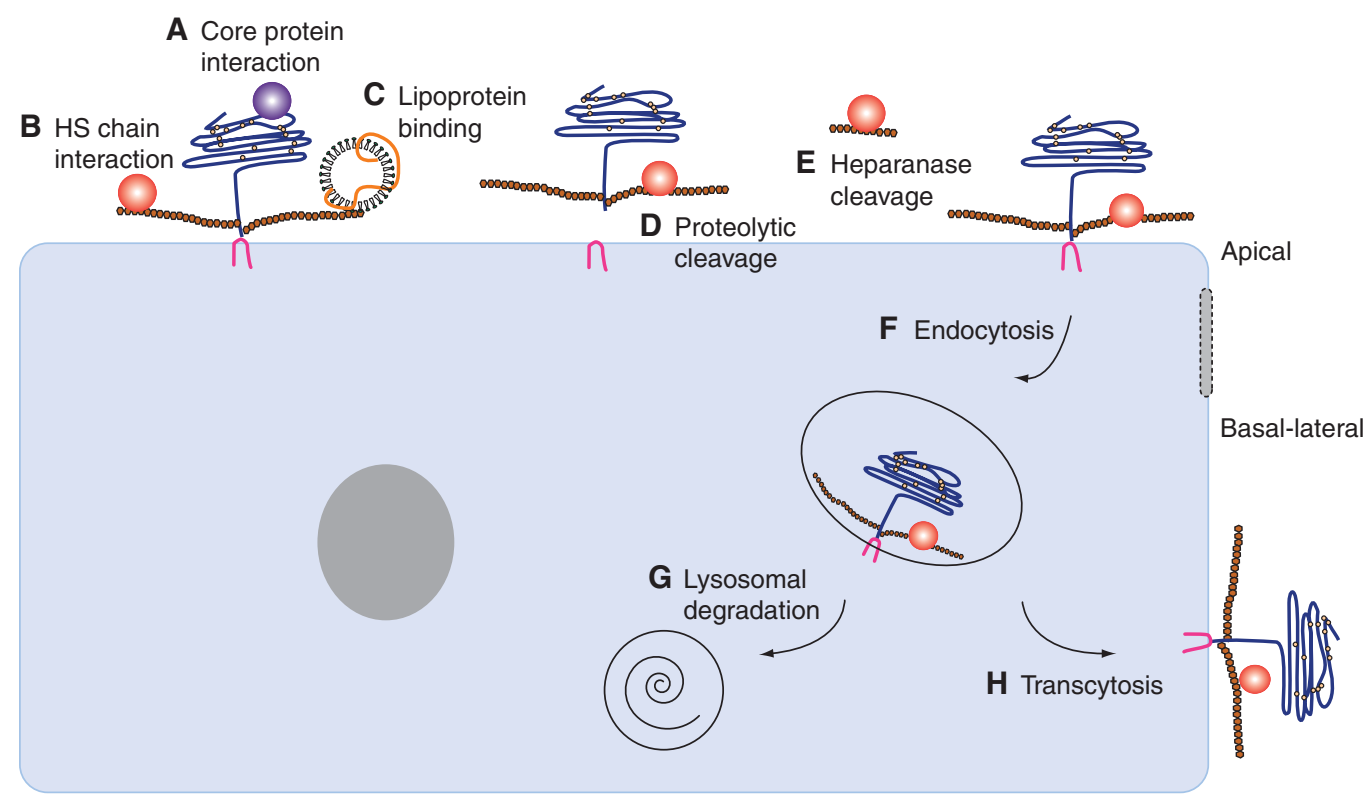

Figure 5. Regulations of cell-surface heparan sulfate proteoglycans. HSPGs can interact with morphogens directly either through their core proteins $(A)$ or HS GAG chains $(B)$. HSPGs also recruit lipoprotein particles by HS GAG chains $(C)$. Proteolytic processing leads to the shedding of cell-surface HSPGs from the membrane $(D)$, and heparanase cleaves the HS GAG chains, releasing bound morphogens $(E)$. Cell-surface HSPGs are actively taken up by endocytosis $(F)$, and then targeted to lysosome degradation $(G)$ or transported from apical membrane to basal-lateral membrane by transcytosis $(H)$.

How do HSPGs assist in the spread of lipid-linked morphogens? Recent studies have shown that both $\mathrm{Hh}$ and $\mathrm{Wg}$ can associate with lipoproteins in vivo and that lipophorin is important for their long-range signaling activity (Panakova et al. 2005) (Fig. 5C). Interestingly, lipophorin binds to the HS GAG chains of Dally and Dlp and can be recruited to the cell membrane by these proteins (Eugster et al. 2007). Thus, HSPGs might regulate $\mathrm{Hh}$ restricted diffusion, at least in part, by interacting with the lipoprotein carrier.

The other two extracellular components of Hh signaling pathways were also found to be HS GAG binding proteins. Shifted (Shf) is a homolog of human Wnt inhibitory factor (WIF), but it is required for Hh stability and diffusion (Glise et al. 2005; Gorfinkiel et al. 2005). Shf protein level is reduced in HSPG mutant clones. Moreover, Shf protein colocalizes with Dlp in wild-type tissues. These data point to a role of Shf in strengthening HSPG/Hh interaction, possibly by functioning as a bridge between them. Ihog, a member of the conserved $\mathrm{Ig} /$ fibronectin superfamily, is an Hh-binding protein essential for the reception of Hh signal (McLellan et al. 2006; Tenzen et al. 2006; Wilson and Chuang 2006; Yao et al. 2006; Zhang et al. 2006). Recent experiments showed that Ihog can bind to heparin (McLellan et al. 2006). Heparin binding can induce Ihog dimerization and is required to mediate high-affinity interactions between Ihog and Hh (McLellan et al. 2006). As ihog mutant shows strong genetic interaction with $d l p$ in Hh signaling, it would be interesting to determine whether Dlp and Ihog can work together in regulating Hh signaling and distribution (Yao et al. 2006).

\section{Roles of HSPGs in BMP Signaling and Distribution}

Drosophila Dpp, the ortholog of vertebrate BMP2 and BMP4, is a target of Hh signaling. Dpp is induced in a stripe of cells adjacent to the AP boundary in wing discs (Zecca et al. 
1995) (Fig. 4). Dpp spreads toward both A and $\mathrm{P}$ distal cells to act as a long-range morphogen by inducing expression of its target genes including spalt (sal) and optomotor-blind (omb) (Lecuit et al. 1996; Nellen et al. 1996; Affolter and Basler 2007). Biochemical studies have shown that both Dpp and BMP2 are heparin-binding proteins (Ruppert et al. 1996; Groppe et al. 1998). In mutant clones of HS GAG biosynthetic enzymes including $s f l$, $t t v$, botv, sotv, both Dpp signaling activity and extracellular level of GFP-Dpp are significantly reduced (Belenkaya et al. 2004; Bornemann et al. 2004; Han et al. 2004b; Takei et al. 2004). In addition, clones of only a few cells wide can effectively block GFP-Dpp movement, suggesting that Dpp moves from cell to cell along the epithelium sheet through a restricted diffusion mechanism (Belenkaya et al. 2004) (Fig. 1A).

Both Dally and Dlp play important roles in Dpp signaling and its gradient formation. Dally mutants show various dpp-like patterning defects and show genetic interactions with the dpp signaling pathway (Nakato et al. 1995; Jackson et al. 1997). Ectopic expression of Dally results in enhanced Dpp signaling in the wing disc (Fujise et al. 2003). These data suggest a positive role of Dally in Dpp signaling. Recent data suggest that Dally regulates Dpp signaling and gradient by stabilizing Dpp on the cell surface (Akiyama et al. 2008). In addition, Dpp mobility is biased toward cells with higher Dally level (Crickmore and Mann 2007). Such activity of Dally may be important to attract Dpp gradient to the lateral edge of the disc. Finally, Dally and Dlp are partially redundant in Dpp signaling and gradient formation because removal of both Dally and Dlp shows stronger defects in Dpp signaling and reductions in extracellular Dpp levels (Belenkaya et al. 2004).

The BMP signaling pathway requires a plethora of extracellular regulatory components (O'Connor et al. 2006; Bier 2008). In addition to direct binding of Dpp, HSPGs could regulate Dpp signaling and gradient formation through interaction of these proteins. Indeed, a recent work showed that crossveinless-2 (CV2), a key component in Dpp signaling, can bind Dally in cell culture and that levels of extracellular CV2 are substantially reduced in botv clones (Serpe et al. 2008).

\section{Roles of HSPGs in Morphogen Signaling} and Distribution in Vertebrates

The functions of HSPGs in morphogen gradient formation are less characterized in vertebrates compared with studies in Drosophila. Studies in the Xenopus embryo show that morphogen molecules such as activin and the nodal-related proteins travel through tissue by a diffusion mechanism, but not by transcytosis or by cytonemes (McDowell et al. 2001; Williams et al. 2004; Kinoshita et al. 2006). However, the role of HSPGs in morphogen gradient formation is currently unknown. Knockdown of Xenopus EXT1 caused reduction of Wnt 11 signaling activity required for specifying the dorsal axis, implying HSPGs may control the distribution of Wnt 11 (Tao et al. 2005).

Human mutations in EXT1 and EXT2 cause the autosomal dominant inherited syndrome, hereditary multiple exostoses (Ahn et al. 1995; Stickens et al. 1996). Surprisingly, in contrast to studies in Drosophila in which loss of $t$ tv function leads to reduced $\mathrm{Hh}$ movement, mice carrying a hypomorphic mutation in Ext1 cause an elevated range of signaling activities of Indian hedgehog (Ihh) (Koziel et al. 2004). Recently, Cortes et al. have shown that the brachymorphic (bm) mouse defective in sulfation of chondroitin sulfate proteoglycans shows defects in Ihh signaling and gradient formation in the developing growth plate (Cortes et al. 2009). Further experimental data showed that Ihh binds to the major cartilage chondroitin sulfate proteoglycan (CSPG) aggrecan via its CS chains (Domowicz et al. 2009). These data suggest that HSPGs and CSPGs function in concert to establish an Ihh morphogen gradient in the epiphyseal growth plate, suggesting another level of complexity to understanding how proteoglycans regulate morphogen gradients in various developmental contexts. 


\section{Core Protein versus HS GAG Chains}

The aforementioned studies have illustrated the essential roles of HSPGs in morphogen distribution and signaling. Here, we draw two conclusions from these studies and discuss the relative contribution of HS GAG chains and the core proteins.

First, studies of Wg, Hh, and Dpp morphogens in the wing disc have suggested that HS-mediated restricted diffusion is a major mechanism for morphogen gradient formation, at least in this biological system (Fig. 1A, 5B). In vertebrate neural tubes, it was also shown that interaction between Shh and HSPG can increase the signaling range of Shh morphogen by a restricted diffusion mechanism (Saha and Schaffer 2006). One remaining issue is to determine whether morphogens are transferred actively by the HS GAG chains or whether HSPGs control the stability of morphogens to ensure that it diffuses across a field of cells without being degraded. Importantly, more and more cell surface and secreted proteins are characterized as HS GAG binding proteins. Therefore, HSPGs could affect morphogen gradients by complex mechanisms (Glise et al. 2005; Gorfinkiel et al. 2005; McLellan et al. 2006; Eugster et al. 2007; Serpe et al. 2008). For example, in addition to $\mathrm{Hh}$, HSPGs can also interact with $\mathrm{Hh}$ binding protein Shf, Hh carrier lipophorin, and $\mathrm{Hh}$ coreceptor Ihog. Combined studies of genetics, biochemistry, cell biology, and mathematical modeling are important to provide further insights into the functions of HSPGs in $\mathrm{Hh}$ gradient formation.

Second, a number of studies have shown that different HSPG core proteins have distinct functions in many developmental contexts, rather than being a carrier for HS GAG chains. HSPG core proteins can contribute to the modification of HS GAG chains (Esko and Zhang 1996; Chen and Lander 2001). Moreover, all the Glypican core proteins share a unique, highly conserved amino-terminal globular domain that contains 14 cysteine residues, which is a potent enhancer of preferential HS glycosylation (Chen and Lander 2001). Finally,
Shaping Morphogen Gradients by Proteoglycans

accumulating data demonstrate that the HSPG core proteins can be directly involved in morphogen signaling. The vertebrate glypican-3 (GPC3) core protein can directly bind Shh and inhibit its signaling activity in cultured cells (Capurro et al. 2008). Another study also shows that the GPC3 core protein can form a complex with several Wnt members and stimulate Wnt signaling in tumor cells (Capurro et al. 2005). Thus, GPC3 core protein plays a negative role in Hh signaling, but a positive role in Wnt signaling. Interestingly, we also find that HS GAG mutated Dlp can rescue Hh signaling in $d l p$ mutant embryos and it also can bind and inhibit $\mathrm{Wg}$ signaling in vivo (Yan D. and Lin. X, unpublished data). These results suggest that the Dlp core protein may play a coreceptor role in $\mathrm{Hh}$ signaling but may compete with signaling receptors for Wg. As Dlp is the homolog of mammalian glypican $-4 / 6$, the evolutionarily conserved core protein of glypicans may mediate specific interactions with different morphogens (Filmus et al. 2008).

\section{Regulation of Cell Surface HSPGs}

Because HSPGs are major regulators for morphogen gradient formation, their expression is tightly controlled during development. Both dally and $d l p$ expression is regulated by $\mathrm{Wg}$ and $\mathrm{Hh}$ signaling, forming a feedback loop to fine tune their morphogen gradients (Fujise et al. 2001; Han et al. 2005; Gallet et al. 2008). Recent studies also showed that the Hox selector gene, Ultrabithorax, can modulate Dpp signaling and tissue growth through transcriptional regulation of dally (Crickmore and Mann 2007). Interestingly, the Hippo signaling pathway also modulates different morphogen signaling through transcriptional control of dally and dlp (Baena-Lopez et al. 2008). Finally, $t t v$ and $s f l$ protein translation is controlled through internal ribosome entry sites in early embryonic development, providing another novel mechanism for temporal or tissue-specific regulation of morphogen signaling and distribution (Bornemann et al. 2008). 
Recent studies have also highlighted the importance of intracellular trafficking of HSPGs in morphogen signaling and gradient formation. Once synthesized, HSPGs are transported to specific membrane domains and actively taken up by endocytosis (Bernfield et al. 1999; Kramer and Yost 2003; Bishop et al. 2007) (Fig. 5F). Glypicans are GPIanchored proteins, which are mainly targeted to the apical surface of epithelia in vertebrate cells (Mayor and Riezman 2004). GPI-anchored proteins are also thought to locate in specific membrane microdomains enriched in sphingolipids and cholesterol, called lipid rafts (Mayor and Riezman 2004). A recent report has examined the dynamic distribution of Dlp in living disc tissue (Gallet et al. 2008). By performing an extracellular staining and time course experiment, Gallet et al. showed that apically localized Dlp undergoes internalization and redistribution to the basolateral compartment, a process known as transcytosis (Gallet et al. 2008) (Fig. 5H). Blocking endocytosis by a dominant-negative form of shi causes apical Dlp accumulation, at the expense of basallateral Dlp. Importantly, they showed that endocytosis of Dlp is essential for its positive role in Hh signaling, whereas transcytosis of Dlp is required for Wg spreading (Gallet et al. 2008). On the other hand, Capurro et al. showed that mouse glypican-3 acts as an inhibitor for Shh signaling by inducing Shh endocytosis and lysosomal degradation (Capurro et al. 2008) (Fig. 5G). Further studies are required to understand how endocytosis of glypican-3 and Dlp have opposite roles in $\mathrm{Hh}$ signaling (Beckett et al. 2008; Yan and Lin 2008). These results suggested that HSPGs may control morphogen gradient formation by both restricted diffusion and transcytosis mechanisms.

Finally, levels of cell surface HSPGs can be controlled by a regulated process called shedding (Bernfield et al. 1999; Kramer and Yost 2003). Shedding can occur in multiple ways: The ectodomain of syndecan can be constitutively shed into the conditioned media of cultured cells by proteolytic cleavage, converting syndecan from an activator to a potent inhibitor (Kato et al. 1998). On the other hand, Notum, a member of secreted $\alpha / \beta$ hydrolase family, was shown to cleave Dlp protein at the level of the GPI anchor (Gerlitz and Basler 2002; Giraldez et al. 2002; Kreuger et al. 2004; Traister et al. 2008) (Fig. 5D). As Notum is a negative regulator of Wg signaling, Notum-induced shedding of Dlp might convert Dlp from a membranetethered coreceptor to a secreted antagonist for Wg signaling (Kreuger et al. 2004). Finally, the HS GAG chains can be cleaved by extracellular heparanase, releasing HS-bound growth factors and generating highly active HS fragments (Sanderson et al. 2004) (Fig. 5E). Although HSPGs can be regulated by various shedding mechanisms, the in vivo roles of HSPG shedding are largely unknown. In particular, how this process contributes to morphogen gradient formation awaits further investigations.

\section{CONCLUDING REMARKS}

Over the past decade, intensive studies have illustrated essential roles of HSPGs in morphogen gradient formation. HSPGs can directly influence morphogen gradient formation at various levels, including morphogen movement, signaling, and trafficking. HSPGs can also interact with other molecules such as lipoprotein, which is required for morphogen movement and distribution. In addition to wellestablished functions of HS GAG chains, more recent data clearly shows the essential roles of HSPG protein cores in morphogen signaling and distribution. Given the molecular complexity of HSPGs, further understanding of HSPG functions in morphogen signaling and distribution will require the combination of genetic, cell biological, and biochemical approaches. Determination of HS structures of specific HSPGs by HS GAG sequencing and by advanced mass spectroscopy technique will help elucidate the molecular nature of HSPGmorphogen interactions. Moreover, determination of glypican core protein structures by $\mathrm{X}$-ray crystallography will allow us to define the interaction of glypican core and specific morphogen molecules. Finally, characterization of specific extracellular and cell surface proteins 
interacting with HSPGs will further our understanding of the mechanisms by which these cell surface proteins modulate morphogen gradient.

\section{ACKNOWLEDGMENTS}

We apologize to many investigators whose articles could not be cited because of space constraints. Studies of HSPGs in the Lin lab were supported partially by National Institute of Health (NIH) grants R01 (GM-63891), American Cancer Society (RSG-07-051), and March of Dimes (\#1-FY05-123) to X. Lin. D. Yan is an Albert J. Ryan fellow and was supported by a predoctoral fellowship from American Heart Association.

\section{REFERENCES}

Affolter M, Basler K. 2007. The Decapentaplegic morphogen gradient: From pattern formation to growth regulation. Nat Rev Genet 8: 663-674.

Ahn J, Ludecke HJ, Lindow S, Horton WA, Lee B, Wagner MJ, Horsthemke B, Wells DE. 1995. Cloning of the putative tumour suppressor gene for hereditary multiple exostoses (EXT1). Nat Gen 11: 137-143.

Akiyama T, Kamimura K, Firkus C, Takeo S, Shimmi O, Nakato H. 2008. Dally regulates Dpp morphogen gradient formation by stabilizing Dpp on the cell surface. Dev Biol 313: 408-419.

Baeg GH, Lin X, Khare N, Baumgartner S, Perrimon N. 2001. Heparan sulfate proteoglycans are critical for the organization of the extracellular distribution of Wingless. Development 128: 87-94.

Baeg GH, Selva EM, Goodman RM, Dasgupta R, Perrimon N. 2004. The Wingless morphogen gradient is established by the cooperative action of Frizzled and Heparan Sulfate Proteoglycan receptors. Dev Biol 276: 89-100.

Baena-Lopez LA, Rodriguez I, Baonza A. 2008. The tumor suppressor genes dachsous and fat modulate different signalling pathways by regulating dally and dally-like. Proc Natl Acad Sci 105: 9645-9650.

Basler K, Struhl G. 1994. Compartment boundaries and the control of Drosophila limb pattern by hedgehog protein. Nature 368: 208-214.

Beckett K, Franch-Marro X, Vincent JP. 2008 Glypican-mediated endocytosis of Hedgehog has opposite effects in flies and mice. Trends Cell Biol 18: 360-363.

Bejsovec A, Wieschaus E. 1995. Signaling activities of the Drosophila wingless gene are separately mutable and appear to be transduced at the cell surface. Genetics 139: $309-320$.

Belenkaya TY, Han C, Yan D, Opoka RJ, Khodoun M, Liu H, Lin X. 2004. Drosophila Dpp morphogen movement is independent of dynamin-mediated endocytosis but
Shaping Morphogen Gradients by Proteoglycans

regulated by the glypican members of heparan sulfate proteoglycans. Cell 119: 231-244.

Bellaiche Y, The I, Perrimon N. 1998a. Tout-velu is a Drosophila homologue of the putative tumour suppressor EXT-1 and is needed for Hh diffusion. Nature 394: $85-88$.

Bellaiche Y, The I, Perrimon N. 1998b. Tout-velu is a Drosophila homologue of the putative tumour suppressor EXT-1 and is needed for Hh diffusion. Nature 394: $85-88$.

Bernfield M, Gotte M, Park PW, Reizes O, Fitzgerald ML, Lincecum J, Zako M. 1999. Functions of cell surface heparan sulfate proteoglycans. Annu Rev Biochem 68: 729-777.

Bier E. 2008. Intriguing extracellular regulation of BMP signaling. Dev Cell 15: 176-177.

Binari RC, Staveley BE, Johnson WA, Godavarti R, Sasisekharan R, Manoukian AS. 1997. Genetic evidence that heparin-like glycosaminoglycans are involved in wingless signaling. Development 124: 2623-2632.

Bishop JR, Schuksz M, Esko JD. 2007. Heparan sulphate proteoglycans fine-tune mammalian physiology. Nature 446: 1030-1037.

Bornemann DJ, Duncan JE, Staatz W, Selleck S, Warrior R. 2004. Abrogation of heparan sulfate synthesis in Drosophila disrupts the Wingless, Hedgehog and Decapentaplegic signaling pathways. Development 131: 1927-1938.

Bornemann DJ, Park S, Phin S, Warrior R. 2008. A translational block to HSPG synthesis permits BMP signaling in the early Drosophila embryo. Development 135: 1039-1047.

Cadigan KM, Fish MP, Rulifson EJ, Nusse R. 1998. Wingless repression of Drosophila frizzled 2 expression shapes the Wingless morphogen gradient in the wing. Cell 93: 767-777.

Callejo A, Culi J, Guerrero I. 2008. Patched, the receptor of Hedgehog, is a lipoprotein receptor. Proc Natl Acad Sci 105: 912-917.

Callejo A, Torroja C, Quijada L, Guerrero I. 2006. Hedgehog lipid modifications are required for Hedgehog stabilization in the extracellular matrix. Development 133: 471-483.

Capurro MI, Xiang YY, Lobe C, Filmus J. 2005. Glypican-3 promotes the growth of hepatocellular carcinoma by stimulating canonical Wnt signaling. Cancer Res 65: 6245-6254.

Capurro MI, Xu P, Shi W, Li F, Jia A, Filmus J. 2008. Glypican-3 inhibits Hedgehog signaling during development by competing with patched for Hedgehog binding. Dev Cell 14: 700-711.

Chen RL, Lander AD. 2001. Mechanisms underlying preferential assembly of heparan sulfate on glypican-1. J Biol Chem 276: 7507-7517.

Chen Y, Struhl G. 1996. Dual roles for patched in sequestering and transducing Hedgehog. Cell 87: 553-563.

Cortes M, Baria AT, Schwartz NB. 2009. Sulfation of chondroitin sulfate proteoglycans is necessary for proper Indian hedgehog signaling in the developing growth plate. Development 136: 1697-1706. 
D. Yan and X. Lin

Crickmore MA, Mann RS. 2007. Hox control of morphogen mobility and organ development through regulation of glypican expression. Development 134: 327-334.

Datta S. 1995. Control of proliferation activation in quiescent neuroblasts of the Drosophila central nervous system. Development 121: 1173-1182.

Desbordes SC, Sanson B. 2003. The glypican Dally-like is required for Hedgehog signalling in the embryonic epidermis of Drosophila. Development 130: 6245-6255.

Domowicz MS, Cortes M, Henry JG, Schwartz NB. 2009. Aggrecan modulation of growth plate morphogenesis. Dev Biol 329: 242-257.

Eaton S. 2006. Release and trafficking of lipid-linked morphogens. Curr Opin Genet Dev 16: 17-22.

Eldar A, Rosin D, Shilo BZ, Barkai N. 2003. Self-enhanced ligand degradation underlies robustness of morphogen gradients. Dev Cell 5: 635-646.

Entchev EV, Schwabedissen A, Gonzalez-Gaitan M. 2000 Gradient formation of the TGF-beta homolog Dpp. Cell 103: 981-991.

Esko JD, Selleck SB. 2002. Order out of chaos: Assembly of ligand binding sites in heparan sulfate. Annu Rev Biochem 71: 435-471.

Esko JD, Zhang L. 1996. Influence of core protein sequence on glycosaminoglycan assembly. Curr Opin Struct Biol 6: 663-670.

Eugster C, Panakova D, Mahmoud A, Eaton S. 2007. Lipoprotein-heparan sulfate interactions in the $\mathrm{Hh}$ pathway. Dev Cell 13: 57-71.

Farese RV Jr, Cases S, Ruland SL, Kayden HJ, Wong JS, Young SG, Hamilton RL. 1996. A novel function for apolipoprotein B: Lipoprotein synthesis in the yolk sac is critical for maternal-fetal lipid transport in mice. J Lipid Res 37: 347-360.

Filmus J, Capurro M, Rast J. 2008. Glypicans. Genome Biol 9: 224.

Franch-Marro X, Marchand O, Piddini E, Ricardo S, Alexandre C, Vincent JP. 2005. Glypicans shunt the Wingless signal between local signalling and further transport. Development 132: 659-666.

Fujise M, Izumi S, Selleck SB, Nakato H. 2001. Regulation of dally, an integral membrane proteoglycan, and its function during adult sensory organ formation of Drosophila. Dev Biol 235: 433-448.

Fujise M, Takeo S, Kamimura K, Matsuo T, Aigaki T, Izumi S, Nakato H. 2003. Dally regulates Dpp morphogen gradient formation in the Drosophila wing. Development 130: $1515-1522$.

Gallet A, Ruel L, Staccini-Lavenant L, Therond PP. 2006 Cholesterol modification is necessary for controlled planar long-range activity of Hedgehog in Drosophila epithelia. Development 133: 407-418.

Gallet A, Staccini-Lavenant L, Therond PP. 2008. Cellular trafficking of the glypican Dally-like is required for fullstrength Hedgehog signaling and wingless transcytosis. Dev Cell 14: 712-725.

Gerlitz O, Basler K. 2002. Wingful, an extracellular feedback inhibitor of Wingless. Genes Dev 16: 1055-1059.

Giraldez AJ, Copley RR, Cohen SM. 2002. HSPG modification by the secreted enzyme Notum shapes the Wingless morphogen gradient. Dev Cell 2: 667-676.
Glise B, Miller CA, Crozatier M, Halbisen MA, Wise S, Olson DJ, Vincent A, Blair SS. 2005. Shifted, the Drosophila ortholog of Wnt inhibitory factor-1, controls the distribution and movement of Hedgehog. Dev Cell 8: 255-266.

Gorfinkiel N, Sierra J, Callejo A, Ibanez C, Guerrero I. 2005. The Drosophila ortholog of the human Wnt inhibitor factor Shifted controls the diffusion of lipid-modified Hedgehog. Dev Cell 8: 241-253.

Greco V, Hannus M, Eaton S. 2001. Argosomes: A potential vehicle for the spread of morphogens through epithelia. Cell 106: 633-645.

Gregor T, Bialek W, de Ruyter van Steveninck RR, Tank DW, Wieschaus EF. 2005. Diffusion and scaling during early embryonic pattern formation. Proc Natl Acad Sci 102: 18403-18407.

Groppe J, Rumpel K, Economides AN, Stahl N, Sebald W, Affolter M. 1998. Biochemical and biophysical characterization of refolded Drosophila DPP, a homolog of bone morphogenetic proteins 2 and 4. J Biol Chem 273: 29052-29065.

Hacker U, Lin X, Perrimon N. 1997. The Drosophila sugarless gene modulates Wingless signaling and encodes an enzyme involved in polysaccharide biosynthesis. Development 124: 3565-3573.

Haerry TE, Heslip TR, Marsh JL, O’Connor MB. 1997. Defects in glucuronate biosynthesis disrupt Wingless signaling in Drosophila. Development 124: 3055-3064.

Han C, Belenkaya TY, Khodoun M, Tauchi M, Lin X. 2004a. Distinct and collaborative roles of Drosophila EXT family proteins in morphogen signalling and gradient formation. Development 131: 1563-1575.

Han C, Belenkaya TY, Wang B, Lin X. 2004b. Drosophila glypicans control the cell-to-cell movement of Hedgehog by a dynamin-independent process. Development 131: 601-611.

Han C, Yan D, Belenkaya TY, Lin X. 2005. Drosophila glypicans Dally and Dally-like shape the extracellular Wingless morphogen gradient in the wing disc. Development 132: 667-679.

Hsiung F, Ramirez-Weber FA, Iwaki DD, Kornberg TB. 2005. Dependence of Drosophila wing imaginal disc cytonemes on Decapentaplegic. Nature 437: 560-563.

Hufnagel L, Kreuger J, Cohen SM, Shraiman BI. 2006. On the role of glypicans in the process of morphogen gradient formation. Dev Biol 300: 512-522.

Jackson SM, Nakato H, Sugiura M, Jannuzi A, Oakes R, Kaluza V, Golden C, Selleck SB. 1997. dally, a Drosophila glypican, controls cellular responses to the TGFbeta-related morphogen, Dpp. Development 124: 4113-4120.

Johnson KG, Ghose A, Epstein E, Lincecum J, O'Connor MB, Van Vactor D. 2004. Axonal heparan sulfate proteoglycans regulate the distribution and efficiency of the repellent slit during midline axon guidance. Curr Biol 14: 499-504.

Kato M, Wang H, Kainulainen V, Fitzgerald ML, Ledbetter S, Ornitz DM, Bernfield M. 1998. Physiological degradation converts the soluble syndecan-1 ectodomain from an inhibitor to a potent activator of FGF-2. Nat Med 4: 691-697. 
Khare N, Baumgartner S. 2000. Dally-like protein, a new Drosophila glypican with expression overlapping with wingless. Mech Dev 99: 199-202.

Kicheva A, Pantazis P, Bollenbach T, Kalaidzidis Y, Bittig T, Julicher F, Gonzalez-Gaitan M. 2007. Kinetics of morphogen gradient formation. Science 315: 521-525.

Kinoshita T, Jullien J, Gurdon JB. 2006. Two-dimensional morphogen gradient in Xenopus: Boundary formation and real-time transduction response. Dev Dyn 235: 3189-3198.

Kirkpatrick CA, Dimitroff BD, Rawson JM, Selleck SB. 2004. Spatial regulation of Wingless morphogen distribution and signaling by Dally-like protein. Dev Cell 7: 513-523.

Koziel L, Kunath M, Kelly OG, Vortkamp A. 2004. Ext1-dependent heparan sulfate regulates the range of Ihh signaling during endochondral ossification. Dev Cell 6: 801-813.

Kramer KL, Yost HJ. 2003. Heparan sulfate core proteins in cell-cell signaling. Annu Rev Genet 37: 461-484.

Kreuger J, Perez L, Giraldez AJ, Cohen SM. 2004. Opposing activities of Dally-like glypican at high and low levels of Wingless morphogen activity. Dev Cell 7: 503-512.

Kutty RK, Kutty G, Kambadur R, Duncan T, Koonin EV, Rodriguez IR, Odenwald WF, Wiggert B. 1996. Molecular characterization and developmental expression of a retinoid- and fatty acid-binding glycoprotein from Drosophila. A putative lipophorin. J Biol Chem 271: 20641-20649.

Lander AD. 2007. Morpheus unbound: Reimagining the morphogen gradient. Cell 128: 245-256.

Lander AD, Nie Q, Wan FY. 2002. Do morphogen gradients arise by diffusion? Dev Cell 2: 785-796.

Lecourtois M, Alexandre C, Dubois L, Vincent JP. 2001. Wingless capture by Frizzled and Frizzled2 in Drosophila embryos. Dev Biol 235: 467-475.

Lecuit T, Brook WJ, Ng M, Calleja M, Sun H, Cohen SM 1996. Two distinct mechanisms for long-range patterning by Decapentaplegic in the Drosophila wing. Nature 381: 387-393.

Lin X. 2004. Functions of heparan sulfate proteoglycans in cell signaling during development. Development 131: 6009-6021.

Lin X, Perrimon N. 1999. Dally cooperates with Drosophila Frizzled 2 to transduce Wingless signalling. Nature 400: 281-284.

Lin X, Perrimon N. 2003. Developmental roles of heparan sulfate proteoglycans in Drosophila. Glycoconj J 19: 363-368.

Luders F, Segawa H, Stein D, Selva EM, Perrimon N, Turco SJ, Hacker U. 2003. Slalom encodes an adenosine $3^{\prime}$-phosphate $5^{\prime}$-phosphosulfate transporter essential for development in Drosophila. Embo J 22: 3635-3644.

Lum L, Yao S, Mozer B, Rovescalli A, Von Kessler D, Nirenberg M, Beachy PA. 2003. Identification of Hedgehog pathway components by RNAi in Drosophila cultured cells. Science 299: 2039-2045.

Marois E, Mahmoud A, Eaton S. 2006. The endocytic pathway and formation of the Wingless morphogen gradient. Development 133: 307-317.

Mayor S, Riezman H. 2004. Sorting GPI-anchored proteins. Nat Rev Mol Cell Biol 5: 110-120.
Shaping Morphogen Gradients by Proteoglycans

McDowell N, Gurdon JB, Grainger DJ. 2001. Formation of a functional morphogen gradient by a passive process in tissue from the early Xenopus embryo. Int J Dev Biol 45: 199-207.

McLellan JS, Yao S, Zheng X, Geisbrecht BV, Ghirlando R, Beachy PA, Leahy DJ. 2006. Structure of a heparindependent complex of Hedgehog and Ihog. Proc Natl Acad Sci 103: 17208-17213.

Moline MM, Southern C, Bejsovec A. 1999. Directionality of wingless protein transport influences epidermal patterning in the Drosophila embryo. Development 126: 4375-4384.

Nakato H, Futch TA, Selleck SB. 1995. The division abnormally delayed (dally) gene: A putative integral membrane proteoglycan required for cell division patterning during postembryonic development of the nervous system in Drosophila. Development 121: 3687-3702.

Nellen D, Burke R, Struhl G, Basler K. 1996. Direct and longrange action of a DPP morphogen gradient. Cell 85: $357-368$.

Neumann CJ, Cohen SM. 1997. Long-range action of Wingless organizes the dorsal-ventral axis of the Drosophila wing. Development 124: 871-880.

Nybakken K, Perrimon N. 2002. Heparan sulfate proteoglycan modulation of developmental signaling in Drosophila. Biochim Biophys Acta 1573: 280-291.

O'Connor MB, Umulis D, Othmer HG, Blair SS. 2006. Shaping BMP morphogen gradients in the Drosophila embryo and pupal wing. Development 133: 183-193.

Panakova D, Sprong H, Marois E, Thiele C, Eaton S. 2005. Lipoprotein particles are required for Hedgehog and Wingless signalling. Nature 435: 58-65.

Perrimon N, Hacker U, Sanson B, Tabata T. 2004. Wingless, hedgehog and heparan sulfate proteoglycans. Development 131: 2509-2513.

Ramirez-Weber FA, Kornberg TB. 1999. Cytonemes: Cellular processes that project to the principal signaling center in Drosophila imaginal discs. Cell 97: 599-607.

Ruppert R, Hoffmann E, Sebald W. 1996. Human bone morphogenetic protein 2 contains a heparin-binding site which modifies its biological activity. Eur J Biochem 237: 295-302.

Saha K, Schaffer DV. 2006. Signal dynamics in Sonic hedgehog tissue patterning. Development 133: 889-900.

Sanderson RD, Yang Y, Suva LJ, Kelly T. 2004. Heparan sulfate proteoglycans and heparanase-partners in osteolytic tumor growth and metastasis. Matrix Biol 23: 341-352.

Selva EM, Hong K, Baeg GH, Beverley SM, Turco SJ, Perrimon N, Hacker U. 2001. Dual role of the fringe connection gene in both heparan sulphate and fringedependent signalling events. Nat Cell Biol 3: 809-815.

Serpe M, Umulis D, Ralston A, Chen J, Olson DJ, Avanesov A, Othmer H, O'Connor MB, Blair SS. 2008. The BMP-binding protein Crossveinless 2 is a short-range, concentration-dependent, biphasic modulator of BMP signaling in Drosophila. Dev Cell 14: 940-953.

Spring J, Paine-Saunders SE, Hynes RO, Bernfield M. 1994. Drosophila syndecan: Conservation of a cell-surface heparan sulfate proteoglycan. Proc Natl Acad Sci 91: 3334-3338. 
D. Yan and X. Lin

Steigemann P, Molitor A, Fellert S, Jackle H, Vorbruggen G. 2004. Heparan sulfate proteoglycan syndecan promotes axonal and myotube guidance by slit/robo signaling. Curr Biol 14: 225-230.

Stickens D, Clines G, Burbee D, Ramos P, Thomas S, Hogue D, Hecht JT, Lovett M, Evans GA. 1996. The EXT2 multiple exostoses gene defines a family of putative tumour suppressor genes. Nat Gen 14: 25-32.

Strigini M, Cohen SM. 1997. A Hedgehog activity gradient contributes to AP axial patterning of the Drosophila wing. Development 124: 4697-4705.

Strigini M, Cohen SM. 2000. Wingless gradient formation in the Drosophila wing. Curr Biol 10: 293-300.

Tabata T, Kornberg TB. 1994. Hedgehog is a signaling protein with a key role in patterning Drosophila imaginal discs. Cell 76: 89-102.

Tabata T, Takei Y. 2004. Morphogens, their identification and regulation. Development 131: 703-712.

Takei Y, Ozawa Y, Sato M, Watanabe A, Tabata T. 2004. Three Drosophila EXT genes shape morphogen gradients through synthesis of heparan sulfate proteoglycans. Development 131: 73-82.

Tao Q, Yokota C, Puck H, Kofron M, Birsoy B, Yan D, Asashima M, Wylie CC, Lin X, Heasman J. 2005. Maternal wnt11 activates the canonical wnt signaling pathway required for axis formation in Xenopus embryos. Cell 120: 857-871.

Teleman AA, Cohen SM. 2000. Dpp gradient formation in the Drosophila wing imaginal disc. Cell 103: 971-980.

Tenzen T, Allen BL, Cole F, Kang JS, Krauss RS, McMahon AP. 2006. The cell surface membrane proteins Cdo and Boc are components and targets of the Hedgehog signaling pathway and feedback network in mice. Dev Cell 10: $647-656$.

Torroja C, Gorfinkiel N, Guerrero I. 2004. Patched controls the Hedgehog gradient by endocytosis in a dynamindependent manner, but this internalization does not play a major role in signal transduction. Development 131: $2395-2408$.
Traister A, Shi W, Filmus J. 2008. Mammalian Notum induces the release of glypicans and other GPIanchored proteins from the cell surface. Biochem J. 410: 503-511.

Voigt A, Pflanz R, Schafer U, Jackle H. 2002. Perlecan participates in proliferation activation of quiescent Drosophila neuroblasts. Dev Dyn 224: 403-412.

White RJ, Nie Q, Lander AD, Schilling TF. 2007. Complex regulation of cyp26al creates a robust retinoic acid gradient in the zebrafish embryo. PLoS Biol 5: e304.

Williams PH, Hagemann A, Gonzalez-Gaitan M, Smith JC. 2004. Visualizing long-range movement of the morphogen Xnr2 in the Xenopus embryo. Curr Biol 14: 1916-1923.

Willnow TE, Hammes A, Eaton S. 2007. Lipoproteins and their receptors in embryonic development: More than cholesterol clearance. Development 134: 3239-3249.

Wilson CW, Chuang PT. 2006. New "hogs" in Hedgehog transport and signal reception. Cell 125: 435-438.

Yan D, Lin X. 2008. Opposing roles for glypicans in Hedgehog signalling. Nat Cell Biol 10: 761-763.

Yao S, Lum L, Beachy P. 2006. The ihog cell-surface proteins bind Hedgehog and mediate pathway activation. Cell 125: 343-357.

Zecca M, Basler K, Struhl G. 1995. Sequential organizing activities of engrailed, hedgehog and decapentaplegic in the Drosophila wing. Development 121: 2265-2278.

Zecca M, Basler K, Struhl G. 1996. Direct and long-range action of a wingless morphogen gradient. Cell 87: 833-844.

Zhang W, Kang JS, Cole F, Yi MJ, Krauss RS. 2006. Cdo functions at multiple points in the Sonic Hedgehog pathway, and Cdo-deficient mice accurately model human holoprosencephaly. Dev Cell 10: 657-665.

Zhu AJ, Scott MP. 2004. Incredible journey: How do developmental signals travel through tissue? Genes Dev 18: 2985-2997. 


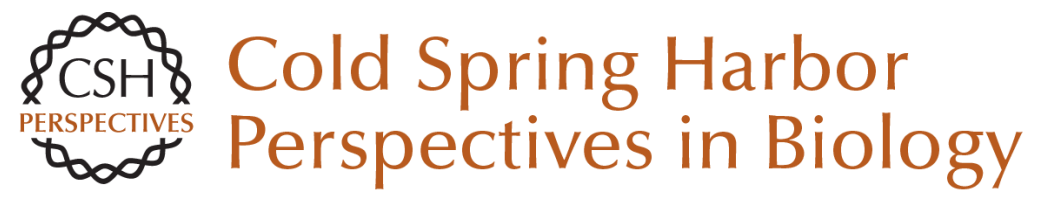

\section{Shaping Morphogen Gradients by Proteoglycans}

Dong Yan and Xinhua Lin

Cold Spring Harb Perspect Biol 2009; doi: 10.1101/cshperspect.a002493 originally published online August 5, 2009

\section{Subject Collection Generation and Interpretation of Morphogen Gradients}

Regulation of Organ Growth by Morphogen Gradients

Gerald Schwank and Konrad Basler

Signaling Gradients during Paraxial Mesoderm

Development Alexander Aulehla and Olivier Pourquié

Morphogen Gradient Formation

Ortrud Wartlick, Anna Kicheva and Marcos

González-Gaitán

Nodal Morphogens Alexander F. Schier

Gradients and the Specification of Planar Polarity in the Insect Cuticle

David Strutt

Vertebrate Limb Development: Moving from

Classical Morphogen Gradients to an Integrated

4-Dimensional Patterning System Jean-Denis Bénazet and Rolf Zeller

Establishing and Interpreting Graded Sonic

Hedgehog Signaling during Vertebrate Neural

Tube Patterning: The Role of Negative Feedback Vanessa Ribes and James Briscoe

Systems Biology of the Self-regulating

Morphogenetic Gradient of the Xenopus Gastrula Jean-Louis Plouhinec and E. M. De Robertis
Gradients in Planarian Regeneration and Homeostasis

Teresa Adell, Francesc Cebrià and Emili Saló

Shaping Morphogen Gradients by Proteoglycans Dong Yan and Xinhua Lin

Forming Patterns in Development without Morphogen Gradients: Scattered Differentiation and Sorting Out

Robert R. Kay and Christopher R.L. Thompson

Robust Generation and Decoding of Morphogen Gradients

Naama Barkai and Ben-Zion Shilo

Models for the Generation and Interpretation of

Gradients

Hans Meinhardt

Graded Dorsal and Differential Gene Regulation in the Drosophila Embryo

Gregory T. Reeves and Angelike Stathopoulos

Chemical Gradients and Chemotropism in Yeast Robert A. Arkowitz

Gradients in the Brain: The Control of the Development of Form and Function in the Cerebral Cortex

Stephen N. Sansom and Frederick J. Livesey

For additional articles in this collection, see http://cshperspectives.cshlp.org/cgi/collection/

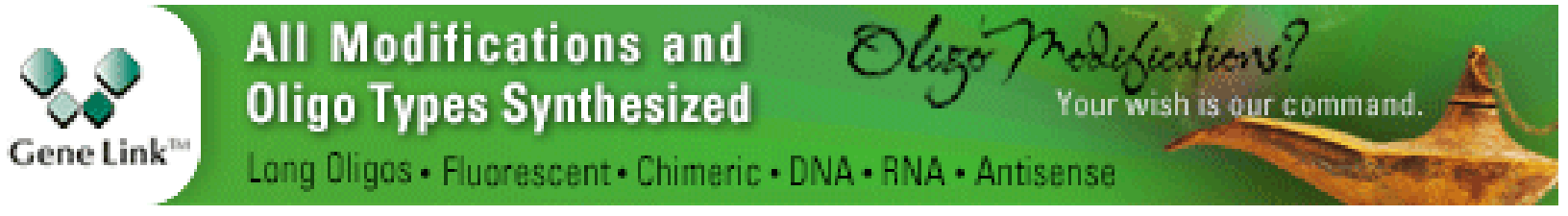


For additional articles in this collection, see http://cshperspectives.cshlp.org/cgi/collection/

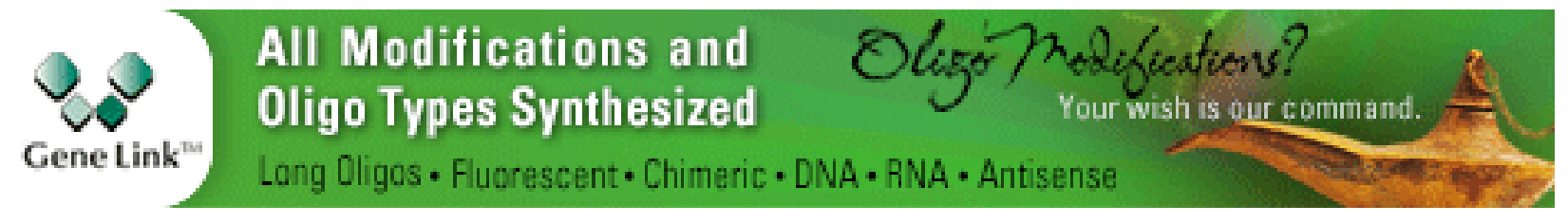

Copyright @ 2009 Cold Spring Harbor Laboratory Press; all rights reserved 